\title{
Inhibition of the Proteasome by Lactacystin Enhances Oligodendroglial Cell Differentiation
}

\author{
Laura A. Pasquini, Pablo M. Paez, Marcos A. N. Besio Moreno, Juana M. Pasquini, and Eduardo F. Soto \\ Departamento de Química Biológica, Instituto de Química y Fisicoquímica Biológica, Facultad de Farmacia y Bioquímica, Universidad de Buenos Aires, \\ Consejo Nacional de Investigaciones Científicas y Técnicas, Buenos Aires 1113, Argentina
}

\begin{abstract}
We have used lactacystin, a specific inhibitor of the $26 \mathrm{~S}$ proteasome, in oligodendroglial cell (OLGc) primary cultures to explore the possible participation of the proteasome- ubiquitin-dependent pathway in the decision of the OLGcs to arrest their proliferation and start differentiation. Addition of lactacystin at various concentrations to cultures containing a majority of OLGc was found to produce their withdrawal from the cell cycle and to induce their biochemical and morphological differentiation, with the appearance of extensive myelin-like sheets. The three classic proteolytic activities of the proteasome were significantly decreased in the lactacystin-treated cultures, and the immunocytochemical analysis showed an increase in the number of 04-, 01-, myelin basic protein-, and myelin proteolipid protein-positive cells and a decrease in A2B5-reacting cells. Quantitative immunochemical evaluation of the expression of certain proteins controlling the cell cycle showed an increase in p $27^{\text {kip } 1}$-, cyclin D-, and cdk4-positive cells, with a decrease in cyclin E- and cdk2-positive cells. In the lactacystin-treated OLGcs, there was a dose-dependent decrease in the number of cells incorporating bromodeoxyuridine and in the activity of the complexes cyclin D-cdk4 and cyclin E-cdk2. Furthermore, increased levels of expression of several STAT factors were found, suggesting that proteasome inhibition in OLGcs could stabilize signals of survival and differentiation that might be processed through the JAK/STAT signaling cascade.
\end{abstract}

Key words: oligodendroglial cells; lactacystin; MG132; differentiation; cyclins; p27 ${ }^{\text {kip1 }}$; JAK/STAT; ubiquitin; proteasome; myelination

\section{Introduction}

The role(s) of ubiquitination and/or proteolytic degradation of protein by the $20 \mathrm{~S}$ and $26 \mathrm{~S}$ proteasomes have received increased attention during recent years, and it is now apparent that these two processes provide an additional point of regulation for many fundamental biological functions. Ubiquitin-dependent proteolysis is integral for degradation of cyclins and cell-cycle progression, generation of peptides presented on the cell surface by the major histocompatibility complex (MHC) class I molecules, and modulation of several transcriptional regulators.

A role for the ubiquitin (Ub)-proteasome pathway in neuronal differentiation has been suggested by a study of the developmental regulation of the expression of Ub enzymes (Bonfanti et al., 1992; Fahrbach and Schwartz, 1994; Flann et al., 1997) and changes in the levels of free and conjugated Ub during nerve growth factor-induced differentiation (Obin et al., 1999). Coincident with these results, neurite outgrowth was induced by proteasome inhibitors such as lactacystin and clastolactacystin $\beta$-lactone and associated with increased levels of ubiquitinated proteins and stabilization of the substrate p53 (Obin et al., 1999).

Oligodendroglial cells (OLGcs) are the myelin-producing cells in the CNS. OLGc progenitors undergo proliferation and differentiation under closely controlled conditions. Stages of maturation of the OLGc progenitors have been identified in in

\footnotetext{
Received Aug. 26, 2002; revised March 12, 2003; accepted March 19, 2003.

This study was supported by a contract grant from the Universidad de Buenos Aires, TB57, and Agencia Nacional de Promoción de Ciencia y Tecnología Programa de Investigacion de Ciencia y Tecnica number 6716.

Correspondence should be addressed to Dr. Eduardo F. Soto, Departamento de Química Biológica, Facultad de Farmacia y Bioquímica, Universidad de Buenos Aires, Junin 956, Buenos Aires 1113, Argentina. E-mail: edufsoto@mail.retina.ar.

Copyright $\odot 2003$ Society for Neuroscience $\quad$ 0270-6474/03/234635-10\$15.00/0
}

vitro studies during the process of differentiation that appear to correspond to similar phenotypes in vivo (Pfeiffer et al., 1993). OLGc precursors are characterized by their reactivity to A2B5 (Levi et al., 1987) and O4 (Sommer and Schachner, 1981; Bansal et al., 1992) monoclonal antibodies. These cells develop into young oligodendroglial multipolar cells that react with both $\mathrm{O} 4$ and $\mathrm{O} 1$ antibodies. Finally, when the cells mature further into fully differentiated OLGcs, they express the enzyme $2^{\prime}, 3^{\prime}$-cyclic nucleotide $3^{\prime}$ phospho-hydrolase (CNPase), myelin basic protein (MBP), and myelin proteolipid protein (PLP).

Differentiation of OLGcs is controlled by numerous factors, including apo-transferrin, which stops migration and proliferation of OLGc precursors and induces their differentiation (Paez et al., 2002). The role of the Ub-proteasome pathway in OLGc differentiation has not been studied. To obtain additional information regarding the possible relationship between the Ubproteasome-dependent pathway and OLGc proliferation and differentiation, we used lactacystin, a specific inhibitor of the $26 \mathrm{~S}$ proteasome (Fenteany et al., 1995), in OLGc primary cultures. We found that the addition of lactacystin to cultures containing a majority of OLGc precursors produces a withdrawal from the cell cycle and induction of biochemical and morphological differentiation, including the appearance of extensive myelin-like sheets.

\section{Materials and Methods}

Materials. Bovine insulin, progesterone, putrescine, sodium selenite, $\mathrm{T}_{3}$, $\mathrm{D}(+)$-galactose, penicillin, 3-(4,5-dimethylthiazol-2-yl)-2,5-diphenyl tetrazolium bromide (MTT), Hoechst 33342, streptomycin, and the substrates used for the determination of the proteolytic activities of the proteasome were obtained from Sigma (St. Louis, MO). Lactacystin and Z-leu-leu-leu-H (MG132) were from Calbiochem (San Diego, CA). DMEM/F12 was purchased from Hyclone (Logan, UT). Antibodies 
against cyclin D, cyclin E, cdk4, cdk2, STAT1, STAT3, p-STAT3, and STAT5b were from Santa Cruz Biotechnology (Santa Cruz, CA). Antip27 ${ }^{\text {kip } 1}$, anti-bromodeoxyuridine (BrdU), anti-neurofilament, and peroxidase-conjugated secondary antibodies were obtained from Sigma. O4, O1, anti-MBP, anti-PLP, anti-GFAP, and A2B5 antibodies were a generous gift from Dr. Anthony Campagnoni (Mental Retardation Research Center, University of California at Los Angeles). Recombinant human PDGF-AA was purchased from PeproTech (Veracruz, Mexico). Histone I was from Upstate Biotechnology Inc. (Lake Placid, NY). Rb (769) was glutathione-S-transferase-(GST)-Rb purified from Santa Cruz Biotechnology. 5-Bromo-2'-deoxyuridine (BrdU) was obtained from Boehringer (Mannheim, Germany). $\left[\gamma^{-}{ }^{32} \mathrm{P}\right]$ ATP was purchased from New England Nuclear (Boston, MA). Fluorsave was from Calbiochem. All other reagents were from Sigma.

Oligodendroglial cell primary cultures. Primary cultures of OLGcs were performed basically as described by McCarthy and de Vellis (1980). Cerebral hemispheres were dissected out from newborn rats, freed of meninges, and dissociated by gentle repetitive pipetting in a mixture of DMEM and Ham's F12 (1:1 v/v) containing $5 \mu \mathrm{g} / \mathrm{ml}$ streptomycin and 5 $\mathrm{U} / \mathrm{ml}$ penicillin, supplemented with $10 \%$ fetal calf serum (FCS). The cell suspensions were seeded in poly-L-lysine-coated $75 \mathrm{~cm}^{2}$ tissue culture flasks. After $14 \mathrm{~d}$ in culture, microglia were separated by shaking for 30 $\mathrm{min}$ in an orbital shaker at $150 \mathrm{rpm} / \mathrm{min}$, and OLGcs were separated from astrocytes by continuous shaking for $24 \mathrm{hr}$ at $240 \mathrm{rpm} / \mathrm{min}$. The cell suspension obtained was filtered through a $15 \mu \mathrm{m}$ mesh filter and then centrifuged at $1500 \mathrm{rpm}$ during $10 \mathrm{~min}$. The pellet containing the OLGcs was resuspended in glial defined medium (GDM: DMEM/F12 supplemented with glucose $4 \mathrm{gm} / \mathrm{l}, \mathrm{NaHCO}_{3} 2.4 \mathrm{gm} / \mathrm{l}$, insulin $25 \mathrm{mg} / \mathrm{l}$, putrescin $8 \mathrm{mg} / \mathrm{l}$, transferrin $50 \mathrm{mg} / \mathrm{l}, \mathrm{T}_{3} 9.8 \mu \mathrm{g} / \mathrm{l}$, progesterone $20 \mathrm{nM}$, sodium selenite $8 \mu \mathrm{g} / \mathrm{l}$, and biotin $10 \mu \mathrm{g} / \mathrm{l}$ (Casaccia-Bonnefil et al., 1996) and plated on poly-L-lysine-coated Petri dishes $\left(2 \times 10^{6}\right.$ cells per dish $)$ for biochemical studies or on poly-L-lysine-coated coverslips placed in multiwell plates $\left(25 \times 10^{3}\right.$ cells per well $)$ for morphological and immunocytochemical studies. Cell cultures evaluated quantitatively with $\mathrm{O} 4$, antineurofilaments, and anti-GFAP antibodies were $95 \%$ pure. In all the experiments, the cell cultures were kept in GDM containing 1\% FCS for $24 \mathrm{hr}$ before treatment with lactacystin. Except when indicated, cells were treated with lactacystin for $72 \mathrm{hr}$ at concentrations of 50, 100, or $200 \mathrm{~nm}$. Controls containing only DMSO $\left(1 \times 10^{-3} \%\right)$, the solvent used as a vehicle for lactacystin, were run in parallel in all cases. A series of experiments using another inhibitor of the proteasome, MG132, were performed to compare the results obtained with lactacystin. The concentrations of MG132 used were 5 and $10 \mathrm{~nm}$, and controls containing $1 \times$ $10^{-3} \%$ ethanol (the solvent used as vehicle) were run in parallel. Samples containing no additions compared with controls containing the vehicle gave similar results.

Evaluation of viability by the MTT assay. The MTT survival assay was performed as described by Mosmann (1983). MTT was dissolved in PBS $(5 \mathrm{mg} / \mathrm{ml})$ and sterilized by passage through a Millipore filter $(0.22 \mu \mathrm{m})$ (Bedford, MA). This solution was added to all wells, and the microplate was incubated at $37^{\circ} \mathrm{C}$ for $45 \mathrm{~min}$. Viable cells with active mitochondria cleave the tetrazolium ring into a visible dark blue formazan reaction product. After the addition of SDS ( $5 \%$ final concentration in $0.005 \mathrm{M}$ $\mathrm{HCl}$ per well) to stop the reaction, the product was quantified by spectrophotometry at $570 \mathrm{~nm}$ (six samples for each experimental condition).

Morphological analysis of oligodendroglial cell complexity. After plating, the OLGc cultures were kept in GDM containing 1\% FCS for $24 \mathrm{hr}$. Then, the cells were treated for $72 \mathrm{hr}$ with the proteasome inhibitor, and the morphology of the treated and control cells was evaluated using the procedure described by Sperber and McMorris (2001) with slight modifications. Individual O4-positive cells were scored according to their morphological complexity in four categories, on the basis of the length and number of primary processes, whether the processes were radially distributed, the relative development of secondary and tertiary processes, and the overall size of the cell, including the process arbor. All cells were scored by an individual who was blind to the experimental conditions.

Immunocytochemistry. OLGcs were fixed for $2 \mathrm{hr}$ in $4 \%$ paraformaldehyde in PBS at room temperature and then treated with $1 \%$ glycine in PBS for $15 \mathrm{~min}$. When permeabilized OLGcs were used, they were incu- bated in $0.1 \%$ Triton X-100 in PBS for 15 min. Samples were blocked with $1 \% \mathrm{BSA}$ in PBS for $2 \mathrm{hr}$ at $37^{\circ} \mathrm{C}$ and incubated overnight at $4^{\circ} \mathrm{C}$ with one of the following primary antibodies: anti-cyclin D (1/300), anticyclin E (1/250), anti-cdk4 (1/500), anti-cdk2 (1/500), anti-p27 ${ }^{\text {kip } 1}$ (1/ $200)$, O4 (1/50), O1 (1/200), A2B5 (1/50), anti-MBP (1/50), and antiPLP (1/400). The coverslips were rinsed and incubated with an antimouse $(1 / 500)$ or anti-rabbit $(1 / 500)$ alkaline phosphatase-conjugated antibody, and the reaction was visualized using nitroblue tetrazolium and 5-bromo-4-chloro-3-indolyl-1-phosphate in the presence of $1 \mathrm{~mm}$ levamisol. Fluorescent antibodies were used in some experiments. Microscopic observations were done with an Olympus BX50 microscope using visible light or by epifluorescence.

After immunostaining, nuclei were stained with the fluorescent dye Hoechst $33342(5 \mu \mathrm{g} / \mathrm{ml}$ in 1\% DMSO) (Oberhammer et al., 1993) to determine the total number of cells. The cell preparation was washed, mounted in Fluorsave, and analyzed by UV light microscopy. Quantitative analysis of the results was done counting the antigen-positive and Hoechst-positive cells in 20 randomly selected fields, which resulted in counts of $>3000$ cells for each experimental condition. Counts of antigen-positive cells were normalized to the counts of total Hoechstpositive cells for each condition.

Proteolytic activities of the $26 \mathrm{~S}$ proteasome. Cell cultures were homogenized in solubilization buffer $(12.5 \mathrm{~mm} \mathrm{KCl}, 135 \mathrm{~mm}$ Tris-acetate at a $\mathrm{pH}$ of 7.5, 80 mм EGTA, $6.25 \mathrm{~mm} \beta$-mercaptoethanol, and $0.17 \%$ octyl- $\beta$ D-glucopyranoside). Lysates were used to assay the three main $26 \mathrm{~S}$ proteasome proteolytic activities: peptidyl glutamyl hydrolase-like (PGhlike), trypsin-like, and chymotrypsin-like activities as described by Beyette et al. (1998). To determine trypsin- or chymotrypsin-like activity, samples containing $100 \mu \mathrm{g}$ of protein were incubated with $100 \mu \mathrm{l}$ of $100 \mathrm{~mm}$ HEPES-HCl (pH 7.5) containing $50 \mu \mathrm{m}$ substrate (Boc-Leu-SerThr-Arg-7-amino-4-methylcoumarin or Ala-Ala-Phe-7-amido-4methylcoumarin, respectively) for $30 \mathrm{~min}$ at $37^{\circ} \mathrm{C}$. The reaction was stopped by addition of $100 \mu \mathrm{l}$ of $220 \mathrm{~mm}$ sodium acetate buffer, and nondegraded protein was precipitated for $30 \mathrm{~min}$ at $4^{\circ} \mathrm{C}$. A clear supernatant was obtained by centrifugation at $400 \times g$ for $30 \mathrm{~min}$ at $4^{\circ} \mathrm{C}$. An aliquot of the supernatant $(200 \mu \mathrm{l})$ was mixed with $2 \mathrm{ml}$ of distilled water, and the fluorescence was measured in a Hitachi (Tokyo, Japan) F1200 spectrofluorometer at excitation and emission wavelengths of 370 and $430 \mathrm{~nm}$, respectively. PGh-like activity was measured in a similar manner, using Clz-Leu-Leu-Glu- $\beta$-naphthylamide as the substrate, followed by precipitation of intact protein by the addition of $300 \mu \mathrm{l}$ of absolute ethanol. After precipitation and centrifugation, $250 \mu \mathrm{l}$ of the supernatant was diluted with $2 \mathrm{ml}$ of distilled water, and the fluorescence was measured at excitation and emission wavelengths of 333 and $450 \mathrm{~nm}$, respectively. Protein-free blanks were included, and a standard curve was prepared with 7-amino-4-methylcoumarin or $\beta$-naphthylamine. The three proteolytic activities were assayed in the presence and absence of $50 \mu \mathrm{M}$ lactacystin.

Incorporation of bromodeoxyuridine. After $24 \mathrm{hr}$ of culture in GDM, OLGcs were treated for $72 \mathrm{hr}$ with 50, 100, or $200 \mathrm{~nm}$ lactacystin. At 72, 48 , or $24 \mathrm{hr}$ before fixation, a pulse of $10 \mu \mathrm{M} \mathrm{BrdU}$ was added to the medium. Control experiments without lactacystin were also performed. The cells were postfixed in ice-cold ethanol (70\%) for $10 \mathrm{~min}$, incubated in $2 \mathrm{~N} \mathrm{HCl}$ for $10 \mathrm{~min}$ to denature the nuclear DNA, and then incubated in $0.1 \mathrm{~m}$ sodium borate for $5 \mathrm{~min}$. The fixed cells were incubated with the anti-BrdU antibody (1/1000), and the immunocomplexes were visualized with ExtrAvidin-peroxidase using 6\% (w/v) 3,3' -diaminobenzidine, $0.003 \%(\mathrm{v} / \mathrm{v}) \mathrm{H}_{2} \mathrm{O}_{2}$ in $0.01 \mathrm{~m}$ Tris-HCl buffer, $\mathrm{pH}$ 7.6.

Cyclin-dependent kinase assays. Cyclin-dependent kinase (cdk) assays were performed according to the procedure described by Gorospe et al. (1996). For the immunoprecipitation of free and bound cdk4, control cells and cells treated with lactacystin for $24-72 \mathrm{hr}$ were washed twice with ice-cold PBS, harvested in cdk4 lysis buffer (50 mM HEPES at a pH of 7.5, 10\% glycerol, $150 \mathrm{~mm} \mathrm{NaCl}, 1$ mM EDTA, 2.5 mм EGTA, 1 mM dithiothreitol, and $0.1 \%$ Tween 20 ) supplemented with phosphatase and protease inhibitors ( $5 \mathrm{~mm} \mathrm{NaF}, 0.1 \mathrm{~mm}$ sodium orthovanadate, $5 \mu \mathrm{g} / \mathrm{ml}$ leupeptin, $50 \mu \mathrm{g} / \mathrm{ml} \mathrm{PMSF}$, and $5 \mu \mathrm{g} / \mathrm{ml}$ pepstatin A), and lysed by repeated passages through a 25 -gauge needle. Cellular debris was removed from the soluble extracts by centrifugation at $16,000 \times g$ for $10 \mathrm{~min}$ at 
$4^{\circ} \mathrm{C}$. After normalizing for protein content, lysates were precleared by incubation with protein A-Sepharose and preimmune rabbit serum (1/ 100 ) for $30 \mathrm{~min}$ at $4^{\circ} \mathrm{C}$. Endogenous cdk4-containing complexes were immunoprecipitated for $3 \mathrm{hr}$ at $4^{\circ} \mathrm{C}$ using a rabbit polyclonal anti-human cdk4 antiserum (1/100). Immunoprecipitates were washed twice with cdk4 lysis buffer and four times with GST-Rb kinase buffer $(50 \mathrm{~mm}$ HEPES at a $\mathrm{pH}$ of 7.5, $10 \mathrm{~mm} \mathrm{MgCl}_{2}, 1 \mathrm{~mm}$ dithiothreitol, $2.5 \mathrm{~mm}$ EGTA, $10 \mathrm{~mm} \beta$-glycerophosphate, $0.1 \mathrm{~mm}$ orthovanadate, $1 \mathrm{~mm} \mathrm{NaF}$ ) and then resuspended in $50 \mu \mathrm{l}$ of GST-Rb kinase buffer. For immunoprecipitation of free and bound cyclin E and cdk2, cells were processed as described above except that they were lysed in cdk2 lysis buffer containing $50 \mathrm{~mm}$ Tris- $\mathrm{HCl}$ at a $\mathrm{pH}$ of 7.4, $250 \mathrm{~mm} \mathrm{NaCl}$, and $0.1 \%$ Triton X-100, supplemented with the inhibitors specified above, and immunoprecipitated for $3 \mathrm{hr}$ at $4^{\circ} \mathrm{C}$ with a rabbit polyclonal anti-human cyclin $\mathrm{E}$ antibody $(1 / 100)$ and rabbit polyclonal anti-human cdk2 antiserum (1/100), respectively. Immunoprecipitates were washed twice with cdk2 lysis buffer and four times with histone I (H1) kinase buffer $(50 \mathrm{~mm}$ Tris- $\mathrm{HCl}$ at a $\mathrm{pH}$ of $7.4,10$ $\mathrm{mm} \mathrm{MgCl}_{2}, 1 \mathrm{~mm}$ dithiothreitol) and then resuspended in $50 \mu \mathrm{l}$ of $\mathrm{H} 1$ kinase buffer.

The kinase activity associated with anti-cdk4 immunocomplexes was assayed in $50 \mu \mathrm{l}$ of GST-Rb kinase buffer containing $10 \mu \mathrm{g}$ of GST-Rb substrate, and that associated with anti-cyclin E and anti-cdk2 immunoprecipitates was assayed in $50 \mu \mathrm{l}$ of $\mathrm{H} 1$ kinase buffer containing $10 \mu \mathrm{g}$ of $\mathrm{H} 1$, in each case supplemented with $2 \mathrm{~mm}$ EGTA and $10 \mu \mathrm{Ci}$ of $\left[\gamma_{-}{ }^{32} \mathrm{P}\right]$ ATP. Reactions were performed for $30 \mathrm{~min}$ at $30^{\circ} \mathrm{C}$. Nonradioactive ATP (final concentration, $30 \mu \mathrm{M}$ ) was then added to each reaction mixture to reduce background signal. Reactions were stopped by the addition of Laemmli sample buffer (Laemmli, 1970), and the reaction products were separated by SDS-PAGE ( $12 \%$ polyacrylamide); the gels were then dried, visualized by autoradiography using a STORM 840 Plus Phosphorimager (Molecular Dynamics, Sunnyvale, CA), and quantified using the Gel-Pro system.

SDS-PAGE and Western blot analysis. For Western blot analysis, cultures were treated with $200 \mathrm{~nm}$ lactacystin for 1 and $2 \mathrm{hr}$ for the evaluation of the group of STAT factors and for $72 \mathrm{hr}$ for $\mathrm{p} 27^{\mathrm{kip} 1}$ and cyclin E. After treatment, the cells were washed with PBS, resuspended, lysed by sonication in $10 \mathrm{~mm}$ Tris- $\mathrm{HCl} \mathrm{pH} 7.5$ buffer containing $1 \%$ SDS and proteins denatured by heating at $95^{\circ} \mathrm{C}$ for $10 \mathrm{~min}$. Protein concentration was determined (Lowry et al., 1951), and aliquots of the different samples (50 $\mu \mathrm{g}$ protein) were subjected to SDS-PAGE (Laemmli, 1970). After electrophoresis, proteins were transferred to polyvinylidene difluoride membranes, blocked overnight at $4^{\circ} \mathrm{C}$ with $5 \%$ BSA, and incubated for $1 \mathrm{hr}$ at $37^{\circ} \mathrm{C}$ with one of the following primary antibodies: anti-p2 $7^{\text {kip } 1}(1 / 500)$, anti-cyclin E (1/500), anti-STAT1, anti-STAT3, anti-pSTAT3, or antiSTAT5b $(1 / 800)$. After washing three times with PBS at $37^{\circ} \mathrm{C}$, the blots were incubated with a peroxidase-conjugated secondary antibody (1/ 3000). Western blots were developed by chemiluminescence using the ECL Plus kit (Amersham Biosciences). Evaluation was done with STORM equipment, and quantitation was performed using the Gel-Pro system.

Statistical analysis. Data are given as means \pm SEM. Student's $t$ test or one-way ANOVA followed by Tukey's test was used for the statistical analysis.

\section{Results}

\section{Effects of lactacystin on OLGc viability}

Cellular viability after $24 \mathrm{hr}$ of incubation, evaluated by the MTT assay (Fig. 1A), showed that at concentrations between 50 and $1000 \mathrm{~nm}$ lactacystin, the viability of the cells compared with controls was markedly increased. At higher concentrations, viability decreased to values similar to those found in controls. In cultures incubated for $72 \mathrm{hr}$ (Fig. $1 \mathrm{~B}$ ), viability increased at lactacystin concentrations up to $200 \mathrm{~nm}$ and decreased thereafter to values significantly lower than those of their corresponding controls. In view of these results, most of the following experiments were done using concentrations up to $200 \mathrm{~nm}$ lactacystin.

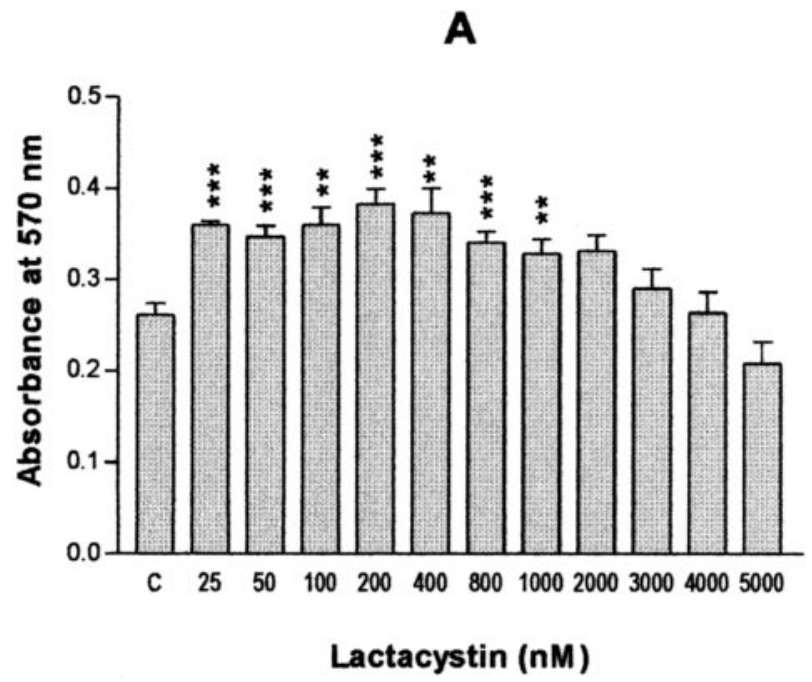

B

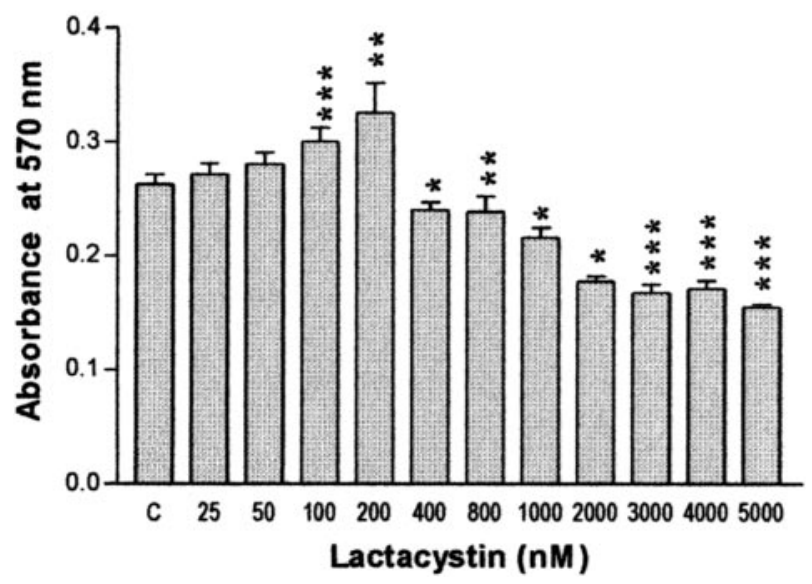

Figure 1. Evaluation of OLGc viability by the MTT assay after treatment of the cells with different concentrations of lactacystin. $A$, Cells treated for $24 \mathrm{hr}$. $B$, Cells treated for $72 \mathrm{hr}$. ${ }^{*} p<$ $0.01 ;{ }^{* *} p<0.001 ;{ }^{* * *} p<0.0001$.

\section{Oligodendrocyte complexity analysis}

Evaluation of the morphological complexity of OLGcs after labeling with an O4 antibody (Sperber and McMorris, 2001) showed that in control cultures, the percentage of cells of low or low-to-medium complexity was $26 \%$, whereas the percentage of cells with medium-to-high complexity was $45 \%$ (Fig. 2). There were very few high-complexity OLGcs. After the cultures had been treated with lactacystin for $72 \mathrm{hr}$, the percentage of cells with low and medium complexity decreased markedly, whereas there was an increase in the percentage of cells of medium-to-high (57-65\%) and high (10-25\%) complexity.

\section{Immunocytochemical analysis of the maturation of OLGcs}

The OLGc cultures treated with lactacystin and their controls were analyzed by immunocytochemistry, using the specific antibodies A2B5, O1, O4, anti-MBP, and anti-PLP. In the treated cells, the intensity of A2B5 reactivity was much lower than in controls, but the reactive cells showed the typical morphological characteristics of immature OLGcs (data not shown). Conversely, the immunoreactivity to $\mathrm{O} 1, \mathrm{MBP}$, and PLP antibodies was much higher than in controls (Fig. 3), and the cells underwent dramatic changes in their morphology, showing a signifi- 


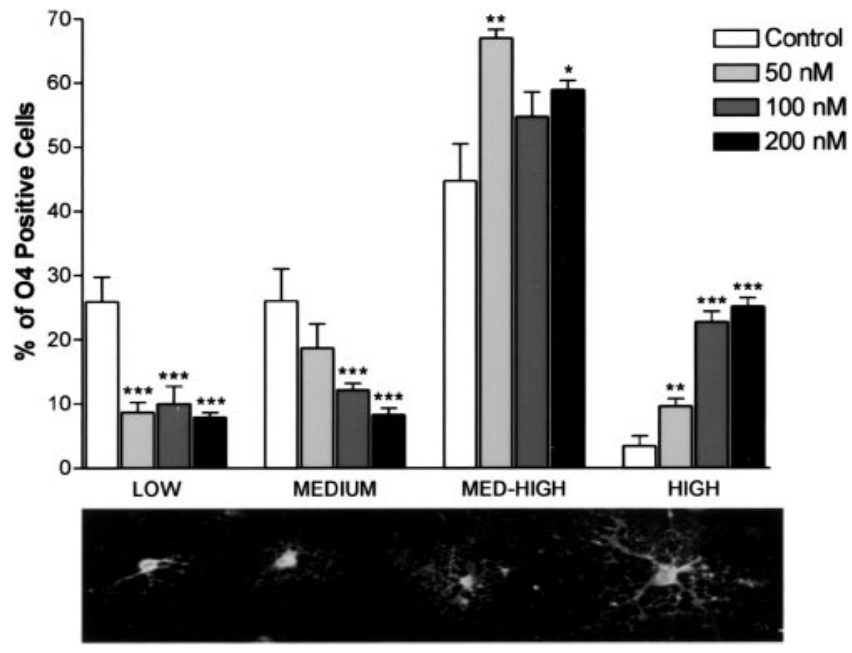

Figure 2. Analysis of the morphological complexity of OLGcs. After plating, the OLGcs were kept in GDM containing $1 \% \mathrm{FCS}$ for $24 \mathrm{hr}$. After treatment for $72 \mathrm{hr}$ with different concentrations of lactacystin, cells were immunolabeled with an 04 antibody, and the morphological complexity of the treated and control cells was evaluated using the procedure described by Sperber and McMorris (2001) (see Materials and Methods). Representative microphotographs of each cell category are shown. Each bar in the graph shows mean distribution of complexities from three independent experiments. Quantitative data of the results are shown at the bottom. ${ }^{*} p<0.05$; ${ }^{* *} p<0.01$; ${ }^{* * *} p<0.001$.

cant increase in the number of primary, secondary, and tertiary processes and an increase in size relative to untreated controls. A particular feature of the action of lactacystin on OLGc differentiation was the appearance in the treated cells of myelin pseudomembranes, typical of more developed oligodendrocytes, which were particularly evident in the cells probed with an $\mathrm{O} 1$ antibody (Fig. 3).

Quantitative evaluation of A2B5 immunoreactivity in the treated cultures revealed that treatment with lactacystin at the lower concentration did not significantly alter the number of A2B5-positive cells, but at higher concentrations (100$200 \mathrm{nM})$, there was a significant decrease in the number of A2B5-reactive cells. Conversely, lactacystin treatment of the cultures resulted in an increase in the number of O1-, O4-, MBP-, and PLPpositive OLGcs (Fig. 4).

Proteolytic activities of the proteasome The activities of the three major proteases of the proteasome in OLGcs incubated for $72 \mathrm{hr}$ in the presence of $200 \mathrm{~nm}$ lactacystin were significantly decreased compared with controls. Trypsin-like activity decreased $17 \%$ with reference to controls, whereas chymotrypsin-like and PGh-like activity was much more affected (38\% and $45 \%$ decreases, respectively) (Fig. 5).

Effects of the inhibition of proteasome activity by MG132

A series of experiments treating the OLGcs with another inhibitor of the activity of the $26 \mathrm{~S}$ proteasome, MG132, were performed to give additional support to the Scale bars, $8.2 \mu \mathrm{m}$. results obtained using lactacystin. MG132 is a very active inhibitor of the proteasome but is not as specific as lactacystin (Fenteany and Schreiber, 1998). Of the three classic enzymatic activities of the proteasome, MG132 inhibits PGh-like and chymotrypticlike activities much more than trypsin-like activity. Because the main purpose of these experiments was to verify that the results obtained with lactacystin were because of the inhibition of the proteasome and not an effect of lactacystin per se, we analyzed only its effects on the degree of inhibition of the proteolytic activities of the proteasome, the viability of the cultured OLGcs (Fig. 6A), and the morphological complexity of the cells (Fig. 6B) using the procedure of Sperber and McMorris (2001) as described above. Cell viability at different concentrations of the inhibitor showed a marked decrease at concentrations $>50 \mathrm{~nm}$. At concentrations of $10 \mathrm{~nm}, \mathrm{PGh}$-like activity was inhibited $41 \%$, chymotryptic-like activity $29 \%$, and tryptic-like activity $10 \%$. Analysis of the morphological complexity of the cells was analyzed at the lowest effective concentrations ( 5 and $10 \mathrm{~nm}$ ). These experiments show that inhibition of the proteasome with MG132 induces a marked increase in the percentage of medium-to-highcomplexity cells and a slight increase in high-complexity cells, particularly at $10 \mathrm{~nm}$, accompanied by a significant decrease in the percentage of the low- and medium-complexity groups (Fig. $6 B$ ). These results are comparable with those obtained with lactacystin, although the effects of MG132 are in general of lower magnitude.

Changes in cell proliferation induced by lactacystin treatment Cell proliferation evaluated by BrdU incorporation in cultures treated with different lactacystin concentrations and during various times is shown in Figure 7. A marked decrease in cell proliferation that was dose and time dependent was observed.

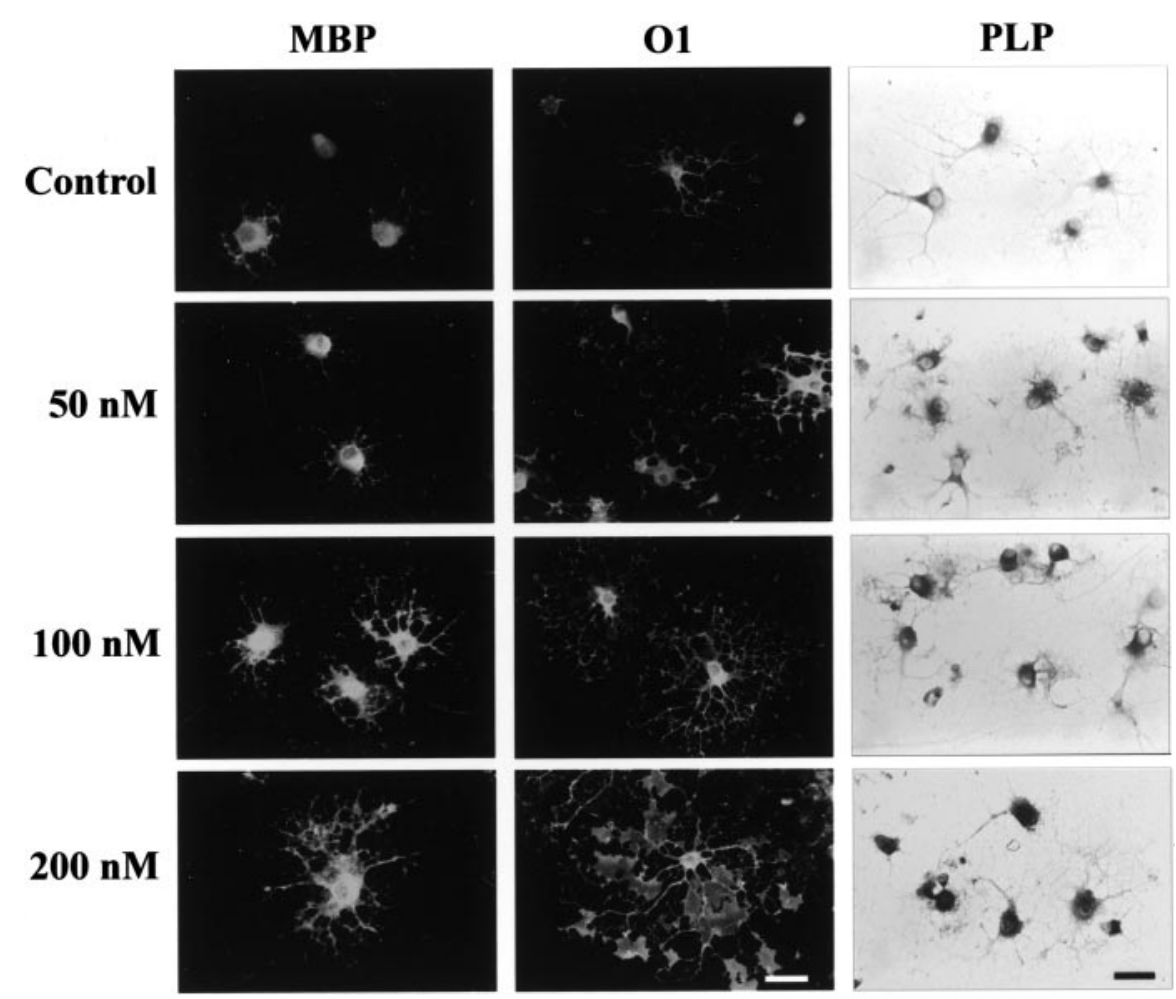

Figure 3. Immunoreactivity of $01, \mathrm{MBP}$, and PLP in cultured $0 \mathrm{LGcs}$ treated for $72 \mathrm{hr}$ with different concentrations of lactacystin. 

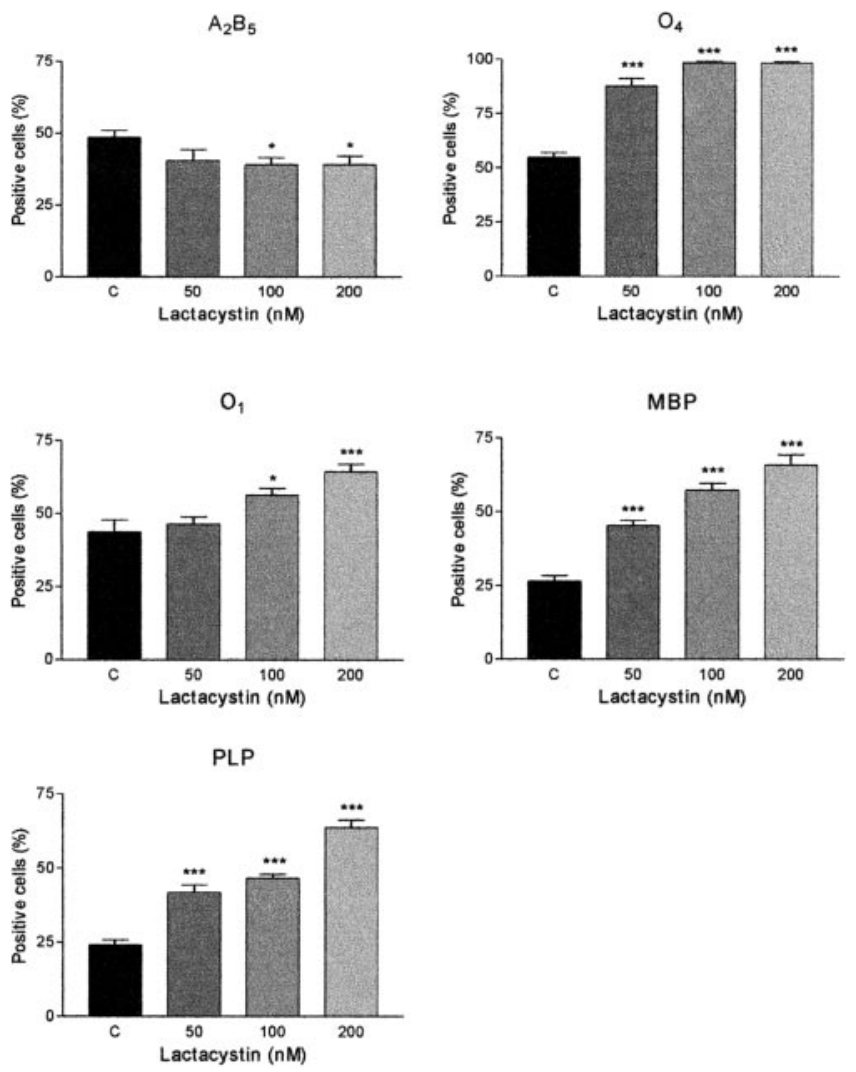

Figure 4. Quantitative evaluation of the immunoreactivity of $A 2 B 5,04, M B P, 01$, and PLP in OLGc cultures treated for $72 \mathrm{hr}$ with different concentrations of lactacystin. For details of the quantification procedure, see Materials and Methods. ${ }^{*} p<0.05$; ${ }^{* *} p<0.01$; ${ }^{* * *} p<0.001$.

\section{Expression of cell-cycle regulation key proteins}

Immunocytochemical evaluation of the expression of $\mathrm{p} 27^{\mathrm{kip} 1}$ showed that in the controls, the reactivity was of higher intensity in the cell body than in the arborizations (Fig. $8 \mathrm{~A}$ ). In the cells treated with lactacystin (Fig. $8 \mathrm{~B}$ ), the expression was much stron-

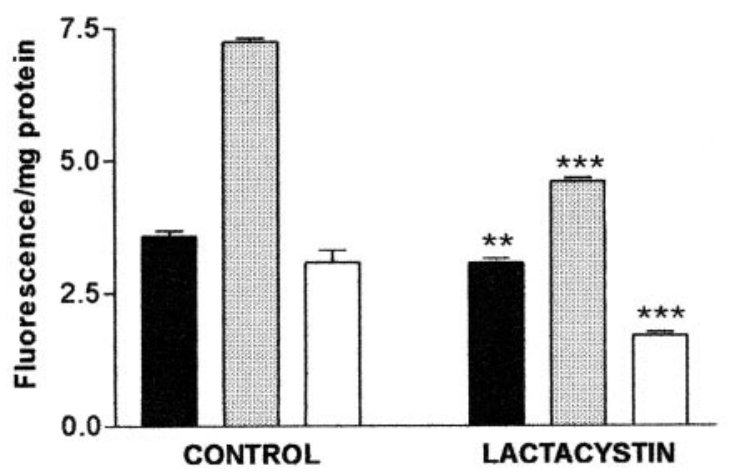

\begin{tabular}{|l|c|}
\hline Activity & $\%$ activity with reference to controls \\
\hline Trypsin-like & $17 \pm 2$ \\
Chymotrypsin-like & $38 \pm 3$ \\
PGh-like & $45 \pm 4$ \\
\hline
\end{tabular}

Figure 5. Proteolytic activities of the proteasome in 0LGes treated with $200 \mathrm{~nm}$ lactacystin for $72 \mathrm{hr}$. Activities were measured in aliquots of cell lysates as described in Materials and Methods. Tryptic-like activity. 慻 Chymotryptic-like activity. $\square$ PGh-like activity. The table shows the percentage of decrease in the activity with reference to control \pm SEM. Results are the mean of three independent experiments. ${ }^{* *} p<0.01 ;{ }^{* * *} p<0.001$.

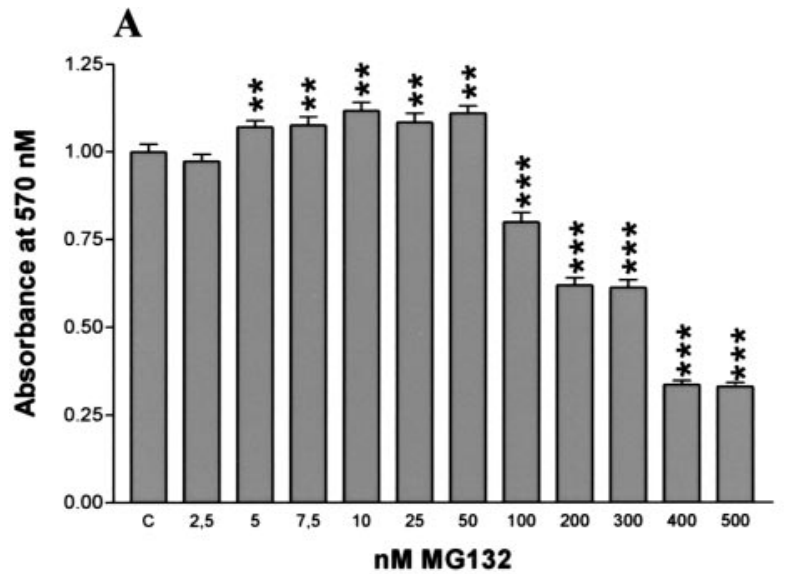

\section{B}

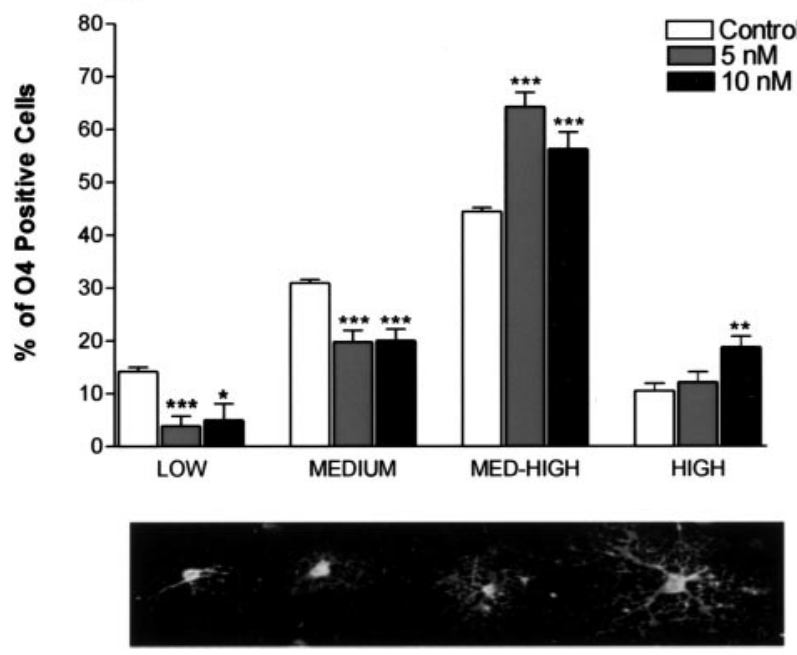

Figure 6. Effect of the inhibition of the proteasome with MG132. A, Evaluation of OLGC viability by the MTT assay after treatment of the cells with different concentrations of MG132 for $72 \mathrm{hr}^{* *} p<0.001$; $^{* * *} p<0.0001$. B, Analysis of the morphological complexity of OLGcs after treatment of the cultures with different concentrations of MG132. Morphological complexity was determined as described in Figure 2. Representative microphotographs of each cell category are shown. Each bar in the graph shows mean distribution of complexities from three independent experiments. ${ }^{*} p<0.05$; ${ }^{* *} p<0.01$; ${ }^{* * *} p<0.001$.

ger than in controls and correlated with the morphological signs of more mature OLGcs. Quantitative evaluation showed that the number of $\mathrm{p} 27^{\text {kip } 1}$-reactive cells increased in the treated cells by $27 \%$ over control values $(p<0.01)$. The changes in $\mathrm{p} 27^{\mathrm{kip} 1}$ were also analyzed by Western blot in cells treated with $200 \mathrm{~nm}$ lactacystin during $72 \mathrm{hr}$. Coincident with the results obtained by immunocytochemistry, there was a clear increase in $\mathrm{p} 27^{\mathrm{kip} 1}$ expression in the treated cells. Densitometric quantification of these Western blots showed that in the cells treated with lactacystin, the expression of p $27^{\mathrm{kip} 1}$ increased $73 \%$ over control values (Fig. $8 D$ ). Immunocytochemical analysis of control and lactacystintreated cultures using anti-cyclin D-specific antibodies (Fig. $9 A, B)$ showed that there was a significant increase in the expression of cyclin D in cells treated with $200 \mathrm{~nm}$ lactacystin. Quantitative evaluation showed that lactacystin treatment at this concentration increased the number of cyclin D-reactive cells $30 \%$ over control values $(p<0.01)$, whereas no significant differences were observed at lower lactacystin concentrations. Immunocytochemistry of cyclin E showed that in the cells treated with $200 \mathrm{nM}$ lactacystin, there was a significant decrease in its expression (Fig. 


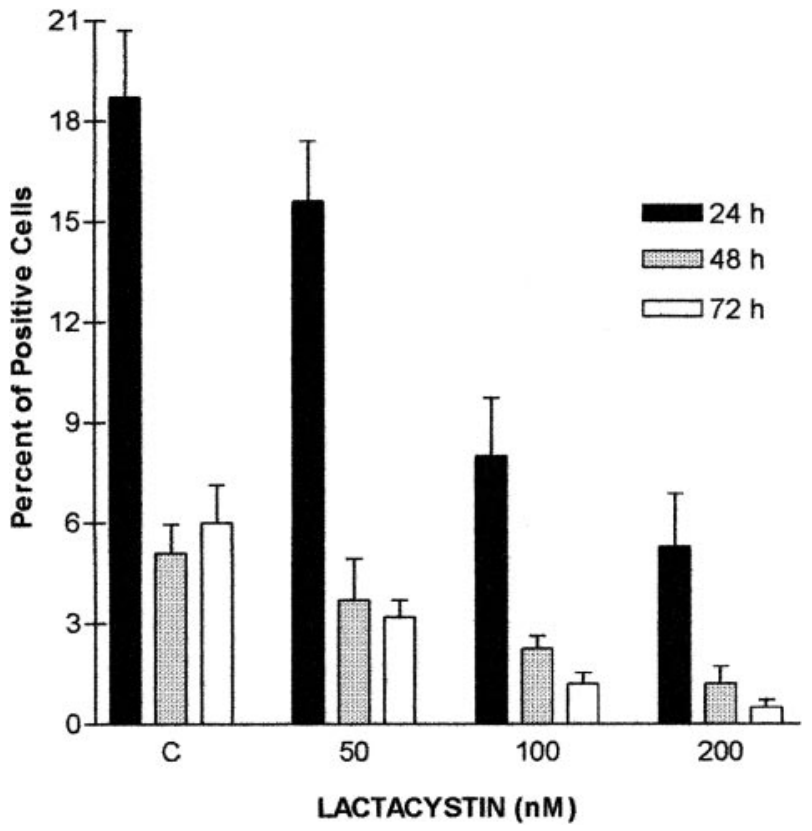

Figure 7. Cell proliferation evaluated by BrdU incorporation in $0 \mathrm{LGc}$ cultures treated for 24 , 48 , and $72 \mathrm{hr}$ with different concentrations of lactacystin. Results are the mean of three independent experiments \pm SEM.

$9 C, D)$, which correlated closely with the characteristic morphological features shown by relatively mature cells. The quantitative evaluation of the lactacystin-treated cells indicated that at this concentration, there was a decrease in the number of cyclin E-reactive cells of $18 \%$ over control values $(p<0.05)$. Because it is known that this cyclin is degraded through the Ub-proteasome pathway, the reduction in immunoreactivity found in OLGc cultures treated with lactacystin was an unexpected finding. Considering the possibility that this decrease in cyclin E reactivity in the cell body could be interpreted in different ways (e.g., among other reasons, by a redistribution of the label in a cell with a much larger cytoplasm or with a more extensive branching or by the displacement of the reactivity from the cytoplasm toward the nucleus), we decided to evaluate possible changes in cyclin $\mathrm{E}$ immunoreactivity in the nucleus and in the cytoplasm of control and treated cells. For this purpose, we performed double-labeling experiments using an anti-cyclin E antibody and Hoechst 33342 to stain the nucleus. Using the Image Pro-Plus software program, we found that the distribution of cyclin E reactivity along the cytoplasm and the nucleus was in fact quite similar in control and in the lactacystin-treated cells and that there was an overall decrease in reactivity in both of these structures (results not shown). To give additional support to these findings, we carried Western blots of cyclin E in lactacystin-treated and control cells. The quantitative analysis of these blots, showing that there was a decrease in the expression of cyclin E of $37.5 \%$ in the treated cells (Fig. 9E), confirmed the results of our immunocytochemical studies.

Figure 10 shows the results of the immunocytochemical analysis of a series of cell-cycle markers in OLGcs treated for $72 \mathrm{hr}$ with $200 \mathrm{~nm}$ lactacystin, in cells treated for $72 \mathrm{hr}$ with $20 \mathrm{ng} / \mathrm{ml}$ of PDGF (used as positive proliferating controls), and in untreated controls. PDGF-treated cells show the typical morphological characteristics of OLGc progenitors, as expected (Noble et al., 1988), and high immunoreactivity for cdk 2 is shown in the entire cell body of these cells. In the cells treated with the proteasome
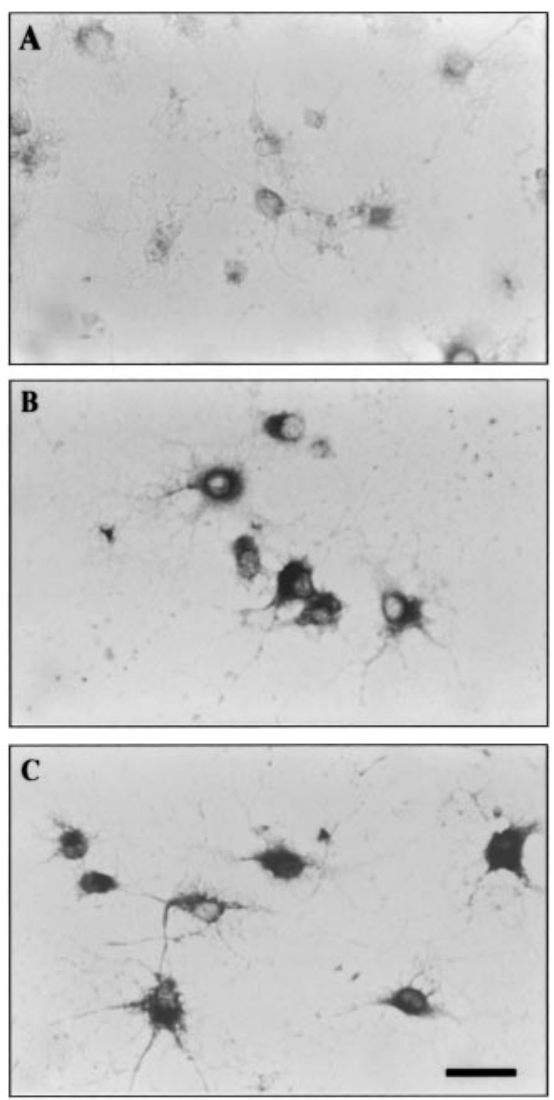

D

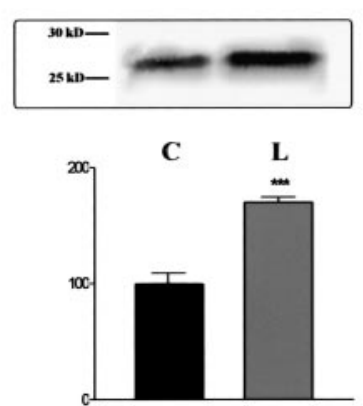

Figure 8. OLGc cultures treated for $72 \mathrm{hr}$ with lactacystin and controls were used for the detection of protein levels of $\mathrm{p} 27 \mathrm{kip} 1$. A, control; $B, 50 \mathrm{~nm}$ lactacystin. C, $100 \mathrm{~nm}$ lactacystin. Scale bar, $8.2 \mu \mathrm{m}$. D, Western blot analysis of p27kip1 of cells treated for $72 \mathrm{hr}$ with $200 \mathrm{~nm}$ lactacystin. Quantitative analysis of the Western blot was performed using the Gel-Pro system. ${ }^{* * *} p<$ 0.001. C, Control; L, lactacystin treated.

inhibitor, which show the morphology of more mature OLGcs, the reactivity for cdk2 is lower than in the PDGF-treated cells and much lower than in the untreated controls. Closely similar results were obtained analyzing cyclin E immunoreactivity. Conversely, for $\mathrm{cdk}$, the immunostaining was high in the lactacystin-treated and in the PDGF-treated cells compared with the untreated controls. Quite similar results were obtained for cyclin D. In the actively dividing PDGF-treated progenitors, $\mathrm{p} 27^{\mathrm{kip} 1}$ reactivity is very much decreased, whereas it is clearly increased in OLGcs treated with lactacystin compared with controls.

Activity of the cyclin-dependent kinase complexes controlling the cell cycle

As mentioned above, the activity of the different cyclindependent kinase complexes was evaluated in cell lysates immunoprecipitated with the specific antibodies and substrates specific 

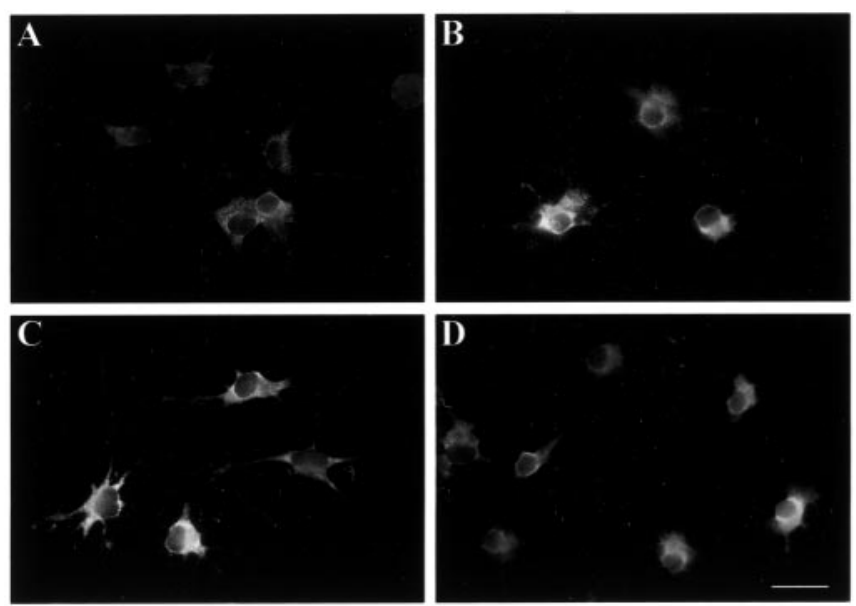

$\mathbf{E}$

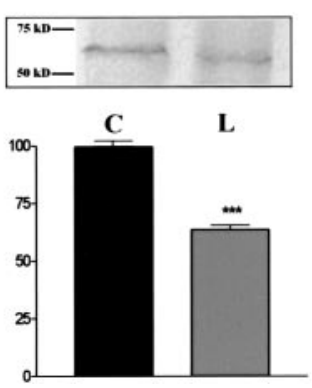

Figure 9. OLGc cultures treated for $72 \mathrm{hr}$ with $200 \mathrm{~nm}$ lactacystin and controls were used for the detection of protein levels of cyclin D. A, control; B, $200 \mathrm{~nm}$ lactacystin. Scale bar, $8.2 \mu \mathrm{m}$. Similar cultures were used for the detection of protein levels of cyclin E. C, Control. D, $200 \mathrm{~nm}$ lactacystin. Scale bar, $8.2 \mu \mathrm{m}$. E, Western blot analysis of cyclin E of cells treated for $72 \mathrm{hr}$ with $200 \mathrm{~nm}$ lactacystin. Quantitative analysis of the Western blot was performed using the Gel-Pro system. ${ }^{* * *} p<0.001$. C, Control; L, lactacystin treated.

to the complex in the presence of $\gamma$-ATP. The activity of cdk4cyclin D was evaluated in lysates immunoprecipitated with anti-cdk4 antibody, using GST-Rb as substrate. Activity was significantly decreased in cultures treated with $200 \mathrm{~nm}$ lactacystin for 24-72 hr compared with control cultures (Fig. 11). The activity of cdk2-cyclin E was evaluated in cultures treated under similar conditions (200 nM lactacystin for 24-72 hr) and in two different lysates immunoprecipitated with either anti-cdk2 or anti-cyclin E, using histone I as a substrate. There was a significant decrease in the activity associated with cdk2 and in that associated with cyclin E (Fig. 11) with reference to controls both at 24 and at $72 \mathrm{hr}$.

\section{Effect of lactacystin on the JAK-STAT signaling pathway}

Keeping in mind that the ubiquitin-proteasome-mediated pathway is involved in the regulation of the JAK/STAT signaling cascade and that this pathway has been found to be active in OLGcs (Dell'Albani et al., 1998), we evaluated the expression of STAT1, STAT3, p-STAT3, and STAT5b to explore one of the possible mechanisms that could be involved in the increased differentiation of the OLGcs that occurs after inhibition of the proteasome with lactacystin. The cultures were treated with lactacystin for only up to $2 \mathrm{hr}$, because changes in this signaling pathway are known to occur early and to be transient. Western blot analysis of these factors showed that in the lactacystin-treated cells, there was a significant increase in the expression of STAT3, p-STAT3, and STAT5b, whereas no significant changes occurred in the expression of STAT1 (Fig. 12).

\section{Discussion}

In the present study, we investigated the possibility that the ubiquitin-proteasome degradation pathway could be involved in OLGc differentiation, examining the effects on primary OLGc cultures of different concentrations of lactacystin. After $72 \mathrm{hr}$ of treatment with this specific proteasome inhibitor at the selected concentration, it was found that the three major proteolytic activities of the proteasome were significantly decreased, cell viability was increased, and the percentage of O4-, O1-, MBP-, and PLP-positive cells was significantly higher, whereas A2B5positive cells decreased compared with controls. A number of OLGcs were severalfold larger, showing abundant membranous sheets, indicating that lactacystin induces OLGc maturation. Quite similar results obtained with MG132 indicate that the effects of lactacystin on OLGcs are not a result of the presence of lactacystin per se.

Terminal cellular differentiation is generally accompanied by exit from the cell cycle, but the molecular basis of how these two events are coupled is poorly understood. Results obtained in p $27^{\text {kip } 1}$ knock-out mice suggest that this factor is a key element of the machinery required for the $G_{1}-G_{0}$ transition in O2A cells (Casaccia-Bonnefil et al., 1997). In differentiating cultures of OLGcs, Tang et al. (1998) found a decrease in cdk2 activity and an increase in cdk 5 activity and in $\mathrm{p} 27^{\mathrm{kip} 1}$ protein, whereas Huang et al. (2002) observed decreased cyclin D1, cdk2, and cdk4 kinase activities with persistent expression of cyclin E. Together, these data suggest that OLGcs may withdraw from the cell cycle at the $\mathrm{G}_{1}-\mathrm{G}_{0}$ transition, through inactivation of cdk activity, possibly initiated by an increase in the amount of $\mathrm{p} 27^{\mathrm{kip} 1}$ and that $\mathrm{cdk} 5$ may have a role in the differentiation of OLGcs.

Pagano et al. (1995) demonstrated that the levels of $\mathrm{p} 27^{\text {kip } 1}$ are regulated post-translationally by Ub-dependent degradation. In our cultures, inhibition of the $26 \mathrm{~S}$ proteasome activity produces an inhibition of $\mathrm{p} 27^{\mathrm{kip} 1}$ degradation, resulting in a striking increase of its levels, which could be signaling the cells to withdraw from the cell cycle and to proceed to their final differentiation. This increase could explain the decrease in cyclin D-cdk4 and cyclin E-cdk2 activities that we observed. Levels of cyclin D are also controlled by degradation through the Ub-dependent pathway (Diehl et al., 1997). We have found a small increase in the amount of this protein that was not paralleled by an increase in the cyclin D-cdk4 complex activity, probably because of an inactivation or sequestration by $27^{\text {kip } 1}$ (Sherr and Roberts, 1999), which is markedly increased. The diminished activity of the other complex, cyclin E-cdk2, observed could also be because of the increase in $\mathrm{p} 27^{\mathrm{kip} 1}$ and the reduction in the amount of cyclin. Degradation of $\mathrm{p} 27^{\mathrm{kip} 1}$ is promoted by its phosphorylation on Thr ${ }^{187}$ by the cyclin E-cdk2 complex (Montagnoli et al., 1999). The reduced activity of this complex found in the lactacystintreated cells could be contributing to the decreased degradation of $\mathrm{p} 27^{\mathrm{kip} 1}$.

Cyclin E is known to be degraded through the Ub-proteasome pathway. The reduction that we find in OLGc cultures treated with lactacystin, confirmed by Western blot, appears to be a contradictory finding. Cyclin $\mathrm{E}$ is ubiquitinated by two different mechanisms: one of them, which requires the attachment of cyclin $\mathrm{E}$ to $\mathrm{cdk} 2$ and its phosphorylation dependent on the activity of the cyclin E-cdk2 complex (Koepp et al., 2001), would be decreased in the lactacystin-treated OLGcs, because the activity of the complex is diminished. In the second mechanism, ubiquitination occurs on unbound cyclin $\mathrm{E}$ and is independent of phosphorylation (Singer et al., 1999). Because in the lactacystin- 
treated cells, the levels of cdk2 and the activity of the complex cyclin E-cdk2 are decreased, the levels of free cyclin E available to ubiquitination and degradation through this second alternative pathway would be higher. Also, because we use low concentrations of lactacystin, proteasome activity is only partially inhibited. Under these circumstances, it is possible that the OLGcs could attain a different stage of cellular homeostasis in which the levels of different proteins would depend not only on the proteolytic activity of the proteasome but also on the strength of the ubiquitination signaling. Thus, the ubiquitination of cyclin $\mathrm{E}$ unbound to cdk2 and its degradation would be favored, despite the decreased activity of the proteasome produced by lactacystin.

The results presented seem to indicate that there is an accelerated withdrawal from the cell cycle of the cells treated with lactacystin, a finding that is also supported by the time- and dose-dependent decrease of BrdU incorporation into these cells.

The increased expression of MBP in OLGcs treated with lactacystin could result from either an increase in proteins signaling for its transcription or a decrease in its degradation. The overexpression of p $27^{\text {kip } 1}$ in the CG4 cell line but not in 3T3 fibroblasts enhances the expression of luciferase driven by the MBP promotor (Miskimins et al., 2002), and interestingly, this effect is specific to $\mathrm{p} 27^{\mathrm{kip} 1}$, because overexpression of other cell-cycle inhibitors had no effect. These investigators conclude that $\mathrm{p} 27^{\mathrm{kip} 1}$ contributes to oligodendrocyte differentiation by regulating the transcription of the MBP gene. The increased levels of p27 kipl, a factor that, as mentioned above, is degraded through the Ub-proteasome pathway found in OLGc cultures treated with lactacystin, could be inducing withdrawal of the cells from the cell cycle and/or increasing the levels of MBP by an increased level of transcription. MBP might be a possible physiological substrate for the $26 \mathrm{~S}$ proteasome (Akaishi et al., 1996), and proteasome inhibition could explain the observed increase in MBP. However, the fact that other markers of differentiation, such as PLP, are also increased argues against this possibility, suggesting that the enhanced expression of $\mathrm{MBP}$ is most likely caused by either an increase in proteins signaling for differentiation or an increase in transcription factors regulating the synthesis of differentiation markers. Wegner (2000) described that the Fyn-kinase response element in the MBP promoter contains consensus binding elements for members of the $\mathrm{C} / \mathrm{EBP}$ class of basic leucine-zipper transcription factors and for STAT proteins, arguing for a role of these transcription factors in mediating the response of Fyn.

Survival and differentiation phenomena such as those induced by PDGF and CNTF in other cell types are transduced through the JAK-STAT signaling cascade (Vignais et al., 1996). Several observations are consistent with the hypothesis that proteasome-mediated degradation can modulate the activity of
Control
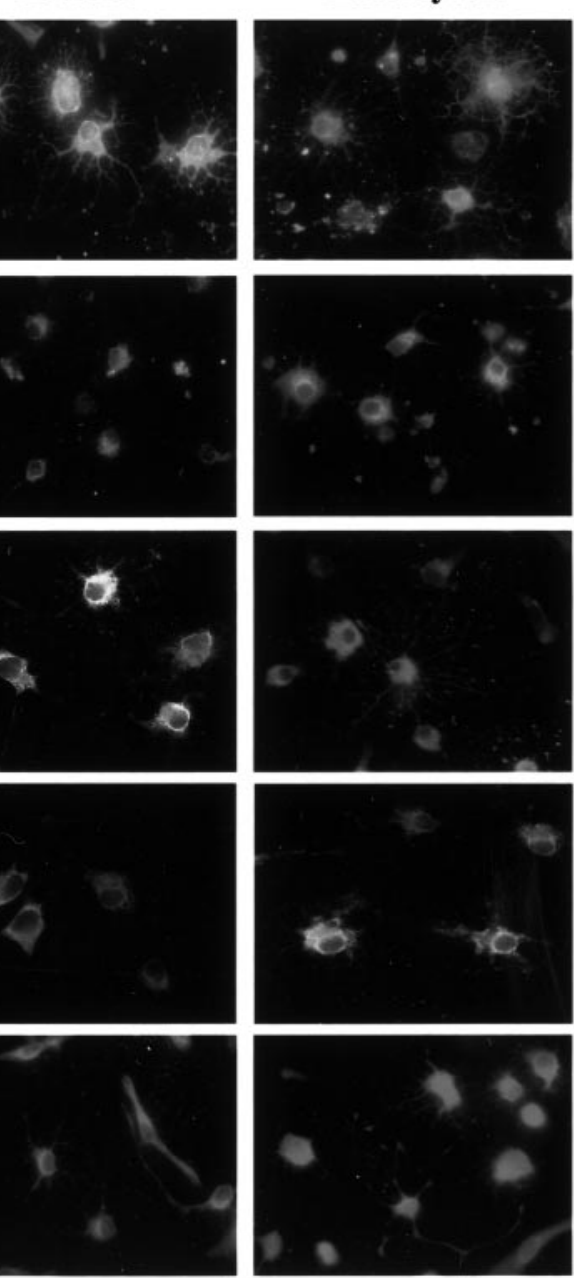

PDGF
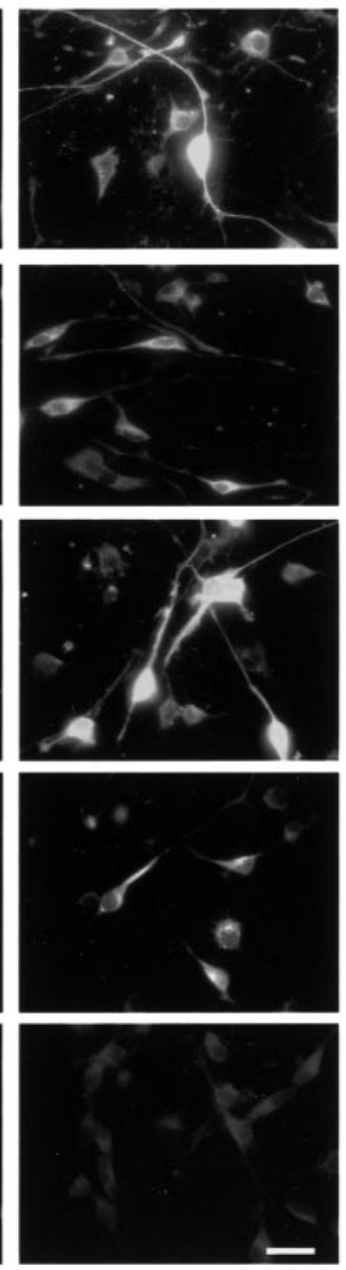

Figure 10. OLGc cultures treated for $72 \mathrm{hr}$ with $200 \mathrm{~nm}$ lactacystin or with $20 \mathrm{ng} / \mathrm{ml} \mathrm{PDGF}$ and controls were used for the immunocytochemical detection of cdk2, cdk4, p27 ${ }^{\mathrm{kip} 1}$, cyclin D, and cyclin E. Scale bar, $8.2 \mu \mathrm{m}$.

the JAK/STAT pathway. This signaling pathway is activated in OLGcs by PDGF and CNTF (Dell'Albani et al., 1998). In SHSY5Y cells, treatment with CNTF induces a rapid tyrosine phosphorylation of STAT3 (Malek and Halvorsen, 1999), and loss of phosphorylated STAT3 was blocked by inhibition of the proteasome, which also stabilized activated STAT1 in interferon- $\gamma$ treated HeLa cells (Kim and Maniatis, 1996), suggesting that the ubiquitin-proteasome pathway may also negatively regulate the amount of activated STAT1.

Because cytokines or growth factors are not present in our OLGc cultures, other possible factors should be responsible for its activation. In this respect, Lin et al. (1999) showed that in HeLa cells, L-thyroxine induces rapid tyrosine phosphorylation and nuclear translocation of STAT3. Transferrin, according to Marta et al. (2002), signals differentiation of OLGcs, at least in part through the activation of MAPKs, which are also known to participate in the activation of STATs (Lin et al., 1999). Although other mechanisms could be involved, it is quite possible that thyroid hormone and/or transferrin, both of which are present at effective concentrations in the defined medium used to culture the OLGcs, could be responsible for STAT3 activation, which could also become more stable as a consequence of proteasome inhibition.

The increase in the levels of expression of STAT3, p-STAT3, 


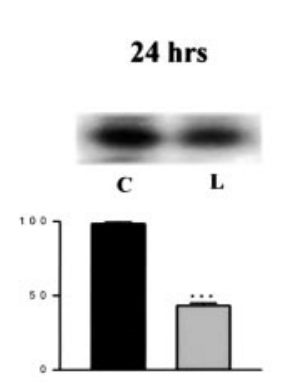

CDK2

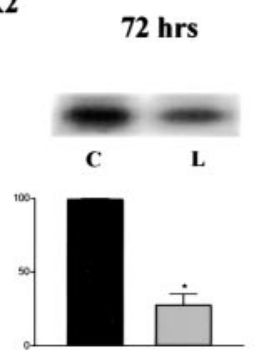

Cyclin E
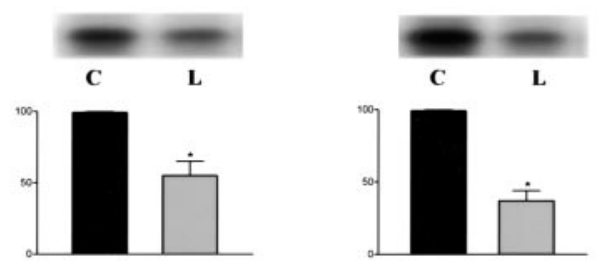

\section{CDK4}
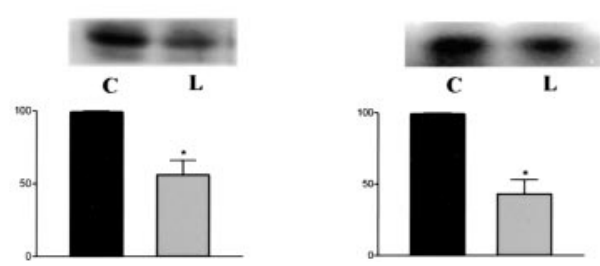

Figure 11. Evaluation of the activity of the cyclin-dependent kinase complexes in lysates of OLGcs after treatment of the cultures with $200 \mathrm{~nm}$ lactacystin for 24 and $72 \mathrm{hr}$. Complexes were immunoprecipitated with anti-cdk2 antibody and anti-cyclin E antibody using histone I as substrate and with anti-cdk4 antibody using GST-Rb as substrate. Radioactivity of the bands was evaluated with a STORM Phosphorimager. C, Control; L, lactacystin treated. Bars show data of the quantitative analysis of each band, which was performed using the Gel-Pro system. ${ }^{*} p<$ $0.05 ;{ }^{* * *} p<0.001$.

and STAT5b found in OLGcs treated with lactacystin suggests that inhibition of the proteasome in OLGcs could activate stabilizing signals of survival and differentiation that might be processed through the JAK/STAT pathway. In view of the fact that the Ub-proteasome pathway is involved in the processing of very large amounts of important proteins, this could be one possible explanation of the significant increase in viability and differentiation that we observe in OLGcs treated with lactacystin.

In conclusion, the results obtained in this study show that the diminished activity of the proteasome activity in OLGc cultures induces (1) rapid differentiation of these cells, evaluated by clear morphological changes and by the appearance of cell markers of differentiation; (2) changes in the levels of expression of certain key regulatory proteins of the cell cycle resulting in a decrease in the activity of the complexes cyclin D-cdk4 and cyclin E-cdk2 and in the number of proliferating cells; and (3) increased levels of expression of several STAT factors, suggesting that inhibition of the proteasome in OLGcs could stabilize signals of survival and differentiation that might be processed through the JAK/STAT signaling cascade

\section{References}

Akaishi T, Shiomi T, Sawada H, Yokosawa H (1996) Purification and properties of $26 \mathrm{~S}$ proteasome from the rat brain: evidence for its degradation of myelin basic protein in a ubiquitin-dependent manner. Brain Res 722:139-144.
STAT 1

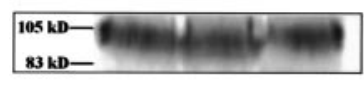

$0^{\circ}$

$60^{\circ}$

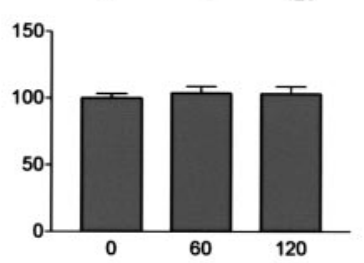

p-STAT 3
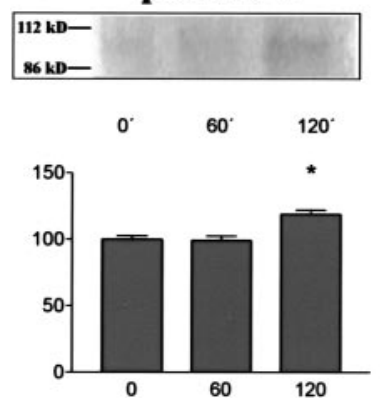

STAT 5b
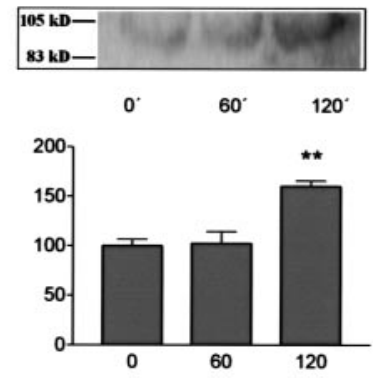

STAT 3
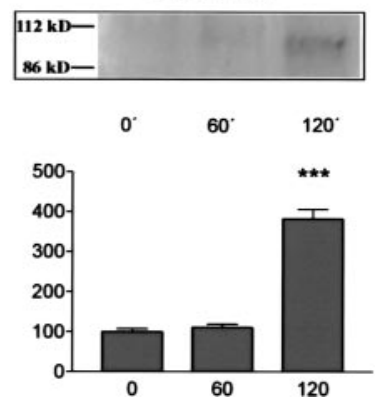

Figure 12. OLGc cultures treated for 1 and 2 hr with $200 \mathrm{~nm}$ lactacystin and controls were used for Western blot analysis of a group of STAT factors. Quantitative analysis of Western blots was performed using the Gel-Pro system. ${ }^{*} p<0.05$; ${ }^{* *} p<0.01$; ${ }^{* *} p<0.001$.

Bansal R, Stefanson K, Pfeiffer SE (1992) Proligodendroblast antigen (POA), a developmental antigen expressed by A007/O4-positive oligodendrocyte progenitors prior to the appearance of sulfatide and galatocerebroside. J Neurochem 58:2221-2229.

Beyette J, Mason GG, Murray RZ, Cohen GM, Rivett AJ (1998) Proteasome activities decrease during dexamethasone-induced apoptosis of thymocytes. Biochem J 332:315-320.

Bonfanti L, Candeo P, Piccinini M, Carmignoto G, Comelli MC, Ghidella S, Bruno R, Gobetto A, Merighi A (1992) Distribution of protein gene product 9.5 (PGP 9.5) in the vertebrate retina: evidence that immunoreactivity is restricted to mammalian horizontal and ganglion cells. J Comp Neurol 322:35-44.

Casaccia-Bonnefil P, Aibel L, Chao MV (1996) Central glia and neuronal populations display differential sensitivity to ceramide-dependent cell death. J Neurosci Res 43:382-389.

Casaccia-Bonnefil P, Tikoo R, Kiyokawa H, Friedrich Jr V, Chao MV, Koff A (1997) Oligodendrocyte precursor differentiation is perturbed in the absence of the cyclin-dependent kinase inhibitor p2 ${ }^{\text {kip1 }}$. Genes Dev 11:2335-2346.

Dell'Albani P, Kahn MA, Cole R, Condorelli DF, Giuffrida-Stella AM, de Vellis J (1998) Oligodendroglial survival factors PDGF-AA and CNTF activate similar JAK/STAT signaling pathways. J Neurosci Res 54:191-205.

Diehl JA, Zindy F, Sherr CJ (1997) Inhibition of cyclin D1 phosphorylation on threonine 286 prevents its rapid degradation via the ubiquitinproteasome pathway. Genes Dev 11:957-972.

Fahrbach SE, Schwartz LM (1994) Localization of immunoreactive ubiquitin in the nervous system of the Manduca sexta moth. J Comp Neurol 343:464-482.

Fenteany G, Schreiber SL (1998) Lactacystin, proteasome function, and cell fate. J Biol Chem 273:8545-8548.

Fenteany G, Standaert RF, Lane WS, Choi S, Corey EJ, Schreiber SL (1995) Inhibition of proteasome activities and subunit specific-amino terminal threonine modification by lactacystin. Science 268:726-731.

Flann S, Hawkes RB, Riederer BM, Rider CC, Beesley PW (1997) Changes in ubiquitin immunoreactivity in developing rat brain: a putative role for ubiquitin and ubiquitin conjugates in dendritic outgrowth and differentiation. Neuroscience 81:173-187.

Gorospe M, Liu Y, Xu Q, Chrest FJ, Holbrook NJ (1996) Inhibition of G1 
cyclin-dependent kinase activity during growth arrest of human breast carcinoma cells by prostaglandin A2. Mol Cell Biol 16:762-770.

Huang Z, Tang XM, Cambi F (2002) Down-regulation of the retinoblastoma protein $(\mathrm{Rb})$ is associated with rat oligodendrocyte differentiation. Mol Cell Neurosci 19:250-262.

Kim TK, Maniatis T (1996) Regulation of interferon- $\gamma$-activated STAT1 by the ubiquitin-proteasome pathway. Science 273:1717-1719.

Koepp DM, Schaefer LK, Ye X, Keyomarsi K, Chu C, Harper W, Elledge SJ (2001) Phosphorylation-dependent ubiquitination of cyclin E by the $\mathrm{SCF}^{\mathrm{Fbw}}$ ubiquitin ligase. Science 294:173-177.

Laemmli UK (1970) Cleavage of structural proteins during the assembly of the head of bacteriophage T4. Nature 227:680-685.

Levi G, Aloisi F, Witkin GP (1987) Differentiation of cerebellar bipotential glial precursors into oligodendrocytes in primary culture: developmental profile of surface antigens and mitotic activity. J Neurosci Res 18:407-417.

Lin HY, Shih A, Davis FB, Davis PJ (1999) Thyroid hormone promotes the phosphorylation of STAT3 and potentiates the action of epidermal growth factor in cultures cells. Biochem J 338:427-432.

Lowry OR, Rosebrough NR, Farr AL, Randall RJ (1951) Protein measurement with Folin phenol reagent. J Biol Chem 193:265-275.

Malek RL, Halvorsen SW (1999) Ciliary neurotrophic factor and phorbol ester each decrease selected stat 3 pools in neuroblastoma cells by proteasome-dependent mechanisms. Cytokine 11:192-199.

Marta CB, Davio C, Pasquini LA, Soto EF, Pasquini JM (2002) Molecular mechanisms involved in the actions of apotransferrin upon the central nervous system: role of the cytoskeleton and of second messengers. J Neurosci Res 69:488-496.

McCarthy KD, de Vellis J (1980) Preparation of separate astroglial and oligodendroglial cell cultures from rat cerebral tissue. J Cell Biol 85:890-902.

Miskimins R, Srinivasan R, Marin-Husstege M, Miskimins WK, CasacciaBonnefil P (2002) p27 Kip1 enhances myelin basic protein gene promoter activity. J Neurosci Res 67:100-105.

Montagnoli A, Fiore F, Eytan E, Carrano AC, Draetta GF, Hershko A, Pagano M (1999) Ubiquitination of p27 is regulated by Cdk-dependent phosphorylation and trimeric complex formation. Genes Dev 1:13:1181-1189.

Mosmann T (1983) Rapid colorimetric assay for cellular growth and survival: application to proliferation and cytotoxicity assays. J Immunol Methods 65:55-63.
Noble M, Murray K, Stroobant P, Waterfield MD, Riddle P (1988) Platelet derived growth factor promotes division and motility and inhibits premature differentiation of the oligodendrocyte type-2 astrocyte progenitor cell. Nature 333:560-562.

Oberhammer F, Fritsch G, Schimied M, Pavelka M, Prinz D, Purchio T, Lassmann H, Schulte-Hermann R (1993) Condensation of the chromatin at the membrane of an apoptotic nucleus is not associated with activation of an endonuclease. J Cell Sci 104:317-326.

Obin M, Mesco E, Gong X, Haas AL, Joseph J, Taylor A (1999) Neurite outgrowth in PC12 cells: distinguishing the roles of ubiquitylation and ubiquitin-dependent proteolysis. J Biol Chem 274:11789-11795.

Paez PM, Marta CB, Besio-Moreno M, Soto EF, Pasquini JM (2002) Apotransferrin decreases migration and enhances differentiation of oligodendroglial progenitor cells in an in vitro system. Dev Neurosci 24:47-58.

Pagano M, Tam SW, Theodora AM, Beer-Romero P, Del Sal G, Chau V, Yew PR, Draetta GF, Rolfe M (1995) Role of the ubiquitin-proteasome pathway in regulating abundance of the cyclin-dependent kinase inhibitor p27. Science 269:682-685.

Pfeiffer SE, Warrington AE, Bansal R (1993) The oligodendrocyte and its many cellular processes. Trends Cell Biol 3:191-197.

Sherr CJ, Roberts JM (1999) Cdk inhibitors: positive and negative regulators of $\mathrm{G}_{1}$-phase progression. Genes Dev 13:1501-1512.

Singer JD, Gurian-West M, Clurman B, Roberts JM (1999) Cullin-3 targets cyclin $\mathrm{E}$ for ubiquitination and controls $\mathrm{S}$ phase in mammalian cells. Genes Dev 13:2375-2387.

Sommer I, Schachner M (1981) Monoclonal antibodies (O1 to O4) to oligodendrocyte cell surfaces: an immunocytological study in the central nervous system. Dev Biol 83:311-327.

Sperber BR, McMorris FA (2001) Fyn tyrosine kinase regulates oligodendroglial cell development but is not required for morphological differentiation of oligodendrocytes. J Neurosci Res 63:303-312.

Tang XM, Strocchi P, Cambi F (1998) Changes in the activity of cdk2 and cdk5 accompany differentiation of rat primary oligodendrocytes. J Cell Biochem 68:128-137.

Vignais ML, Sadowski HB, Watling D, Rogers NC, Gilman M (1996) Platelet-derived growth factor induces phosphorylation of multiple JAK family kinases and STAT proteins. Mol Cell Biol 16:1759-1769.

Wegner M (2000) Transcriptional control in myelinating glia: flavors and spices. Glia 31:1-14. 